SECTION 2. Applied mathematics. Mathematical modeling.

Dyunova Diana Nikolayevna Associate professor, Candidate of Technical Science, North Caucasian Institute of Mining and Metallurgy, Russia

Dunova dn@mail.ru

\title{
MODELING OF PROCESS OF SOUR LEACHING IN PRODUCTION OF ZINC
}

Abstract: The mathematical model of process sour leaching in production of zinc which allows to predict quantitative characteristics of process is offered.

Key words: sour leaching, production of zinc, mathematical model.

\section{УДК 669.054}

\section{МОДЕЛИРОВАНИЕ ПРОЦЕССА КИСЛОГО ВЫЩЕЛАЧИВАНИЯ В ПРОИЗВОДСТВЕ ЦИНКА}

\author{
Аннотация: Предложена математическая модель процесса кислого \\ выщелачивания в производстве цинка, которая позволяет прогнозировать \\ количественные характеристики процесса. \\ Ключевые слова: кислое выщелачивание, производство ичинка, математичекая \\ модель.
}

Выщелачивание продуктов обжига - основной технологический передел цинкового производства, который в значительной мере определяет техникоэкономические показатели производства [1, c.257] Цель процесса кислого выщелачивания связана с обеспечением более полного излечения цинка из обожженного продукта и предотвращением обратного перехода в раствор большого количества осажденных из него примесей, осложняющих последующие процессы гидролитической очистки и отстаивания пульпы в нейтральном цикле [2, с.104].

Основными потоками, поступающими на вход процесса кислого выщелачивания, являются потоки крупных фракций огарка после классификации (пески), нижнего слива нейтральных сгустителей (НСНС), отработанного электролита (ОЭ), растворов цеха переработки окислов (ЦПО), фильтрата. Возмущающими воздействиями, приводящие к изменению состава продуктов кислого выщелачивания, являются химические составы потоков. Выходными потоками являются верхний слив кислых сгустителей (ВСКС) и нижний слив кислых сгустителей (НСКС).

В основе эффективной промышленной реализации выщелачивания лежат теоретические работы, посвященные объяснению сущности протекающих при выщелачивании процессов $[3$, с.23; 4, с.19], их исследованию [5, с.118], интенсификации и оптимизации $[6$, с.23; 7, с.3], автоматизации и создания систем управления $[8$, c.111; 9, с.64]. С целью изучения процесса кислого выщелачивания и его характеристик интерес представляла разработка модели, позволяющей определять количество получаемых продуктов на основе информации о поступающих на переработку материальных потоках и их химических составах.

Полученная математическая модель процесса кислого выщелачивания, представляющая собой систему балансовых соотношений по твердой фазе, жидкой фазе и по составляющим компонентам, приведена в [10, с.25].

Особенности математической модели позволяют перейти к ее топологическому аналогу. На основе уравнений модели процесса кислого выщелачивания построен 
сигнальный граф, отражающий причинно-следственные связи между переменными системы (рис. 1). Вершины графа соответствуют переменным модели, а ветви коэффициентам или передаточным функциям, характеризующим связь между переменными. Решение сигнального графа может быть найдено с помощью операций эквивалентного преобразования [11, с.154]. Топологическая модель процесса была реализована в приложении Simulink вычислительной среды MATLAB.

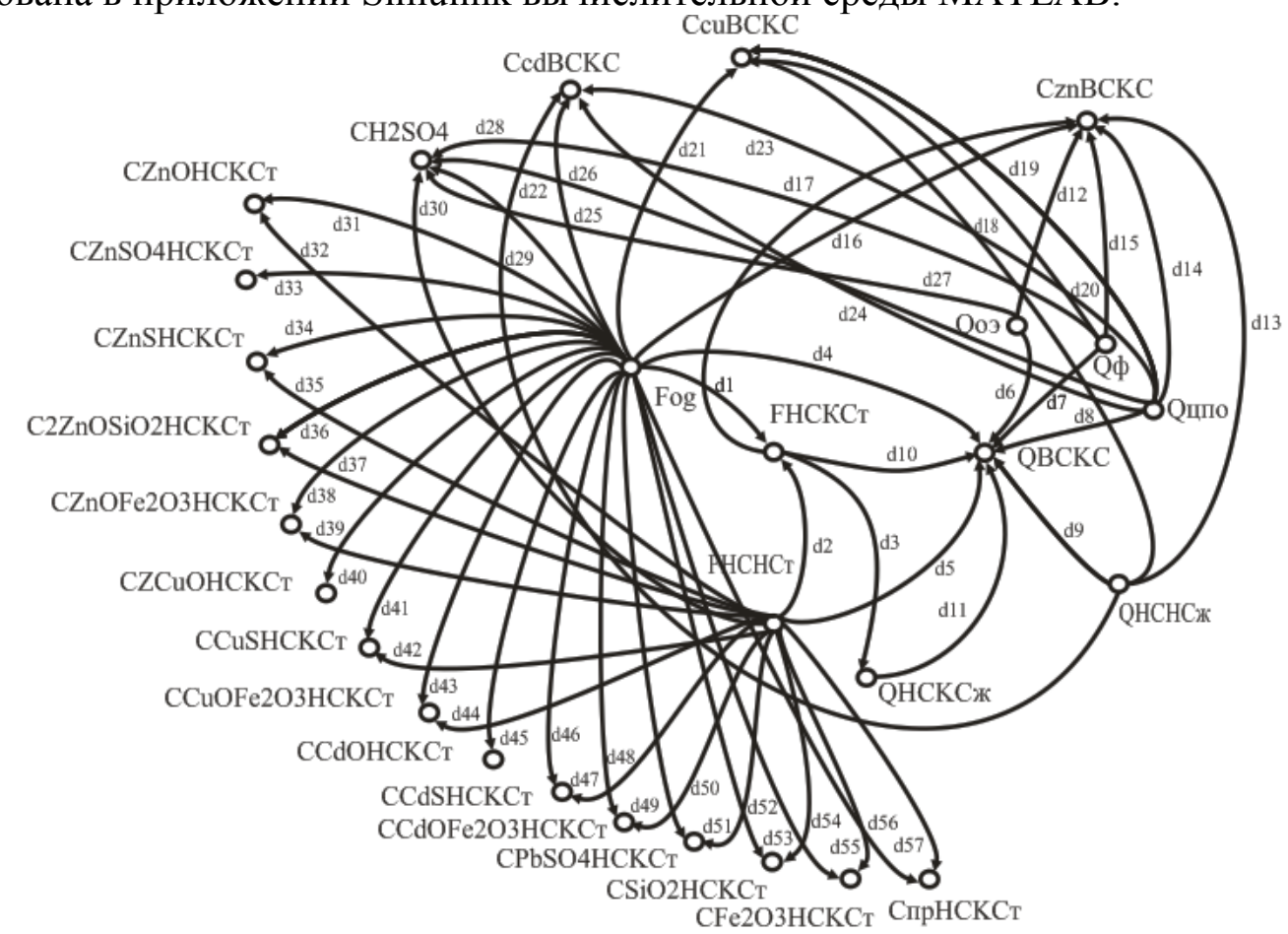

Рисунок 1 - Сигнальный граф процесса кислого выщелачивания цинковых огарков

Математическая модель позволяет определить статические характеристики процесса. Расход ВСКС возрастает с увеличением расхода отработанного электролита (рис. 2). На рис. 3 показана зависимость концентрации цинка в ВСКС от расхода отработанного электролита.

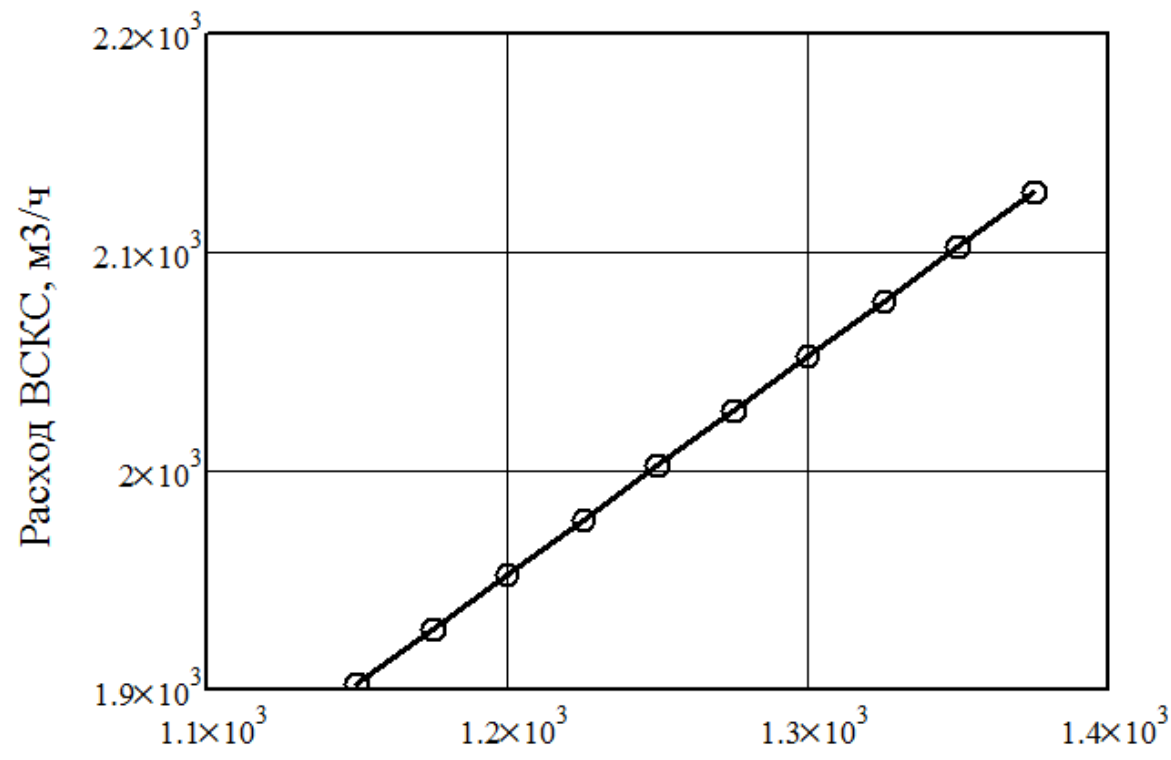

Расход ОЭ, м3/ч

Рисунок 2 - Зависимость расхода ВСКС от расхода отработанного электролита. 


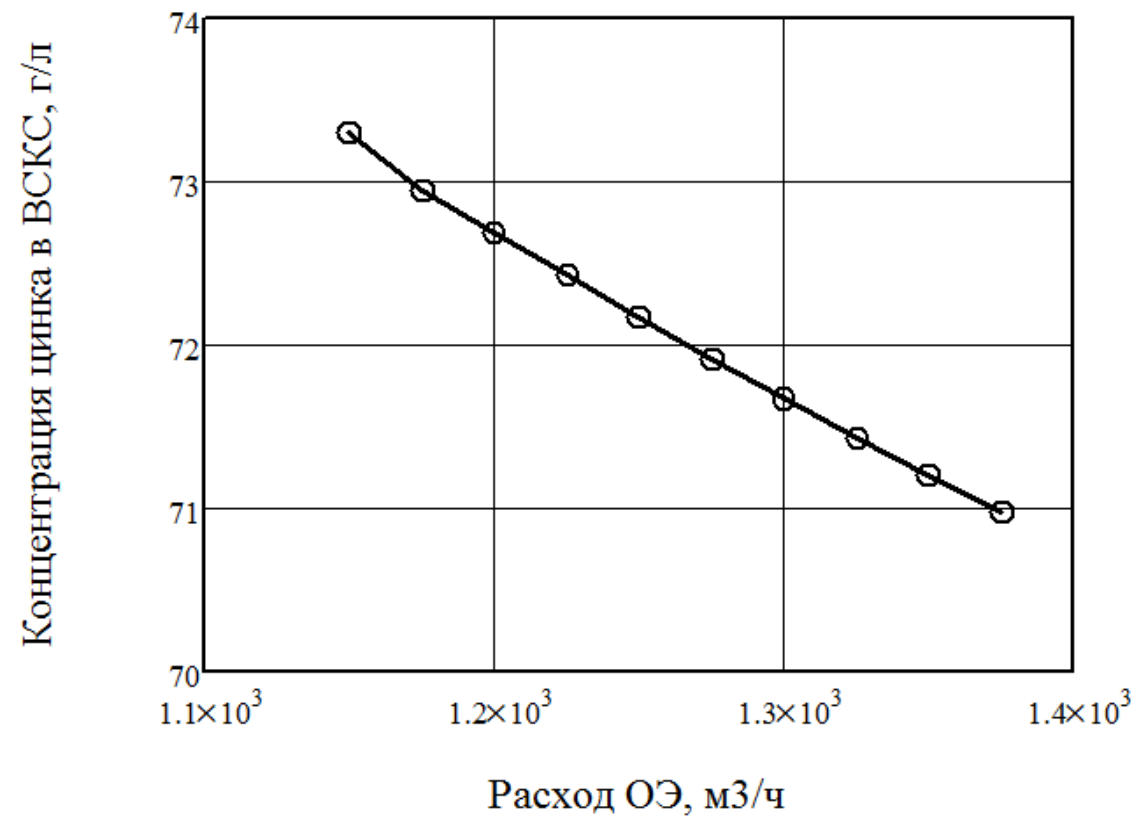

Рисунок 3 - Зависимость концентрации цинка в ВСКС от расхода ОЭ

Разработанная математическая модель процесса предназначена для определения выходных количественных характеристик процесса в виде расходов материальных потоков ВСКС, НСКСж, НСКСт и их покомпонентных составов на основе измерительной информации о расходах и покомпонентных составах входных материальных потоков.

\section{Список литературы}

1. Уткин Н. И. Металлургия цветных металлов. М.: Металлургия, 1985. 216 с.

2. Снурников А. П. Гидрометаллургия цинка. М.: Металлургия, 1981. 384 с.

3. Вигдорчик Е. М., Шейнин А. Б. Математическое моделирование непрерывных процессов растворения. Л.: Химия, 1971. 248 с. 1976. $99 \mathrm{c}$.

4. Доброхотов Г. Н. Гидрометаллургические процессы и аппараты. М.: ЛГИ,

5. Салихов 3. Г. Математическая модель структуры химико-технологической системы для нейтрального выщелачивания цинкового огарка в кипящем слое// Изв. Вузов. Цв. металлургия. 1990. №1. С. 118-121.

6. Дюнова Д. Н. К вопросу оптимизации гидрометаллургического комплекса «выщелачивание - сгущение» // Цветная металлургия. 2004. №4. С. 23-25.

7. Дюнова Д. Н. Динамическая оптимизационная модель процесса выщелачивания цинковых огарков // Цветная металлургия. 2007. № 12. С. 3-5.

8. Буровой И. А. Автоматизация процесса кислого выщелачивания обоженных цинковых концентратов в кипящем слое // Автоматизация технологических процессов цветной металлургии / МИСИС, 1972. Вып. 72. С. 110-114.

9. Салихов 3. Г. Разработка и исследование автоматизированного процесса нейтрального выщелачивания цинковых огарков в кипящем слое / Буровой И. А., Салихов 3. Г. // Отчет по НИР. М., МИСИС. 1976. 170 с.

10. Дюнова Д. Н. Математическая модель процесса кислого выщелачивания цинковых огарков // Труды Международной заочной конференции «Актуальные вопросы современной информатики» / Коломна, 2011. С. 24-28.

11. Кафаров В. В., Перов В. Л., Мешалкин В. П. Принципы математического моделирования химико-технологических систем. М.: Химия, 1974. 354 с. 